\title{
PULSIÓN DE VIDA Y NOMADISMO EN VIENTO SUR, POESÍA EN TERRITORIOS COMPARTIDOS
}

\author{
LIFE PULSION AND NOMADISM IN VIENTO SUR, \\ POESÍA EN TERRITORIOS COMPARTIDOS \\ Paula Tesche \\ Universidad Andrés Bello, Sede Concepción. Concepción, Chile \\ paula.tesche@unab.cl
}

\begin{abstract}
4 sta nota tiene como principal motivación realizar una propuesta de Canálisis del texto de poesía penquista, Viento sur, poesía en territorios compartidos (2016), en el entendido que revela la complejidad del sujeto en vinculación con el territorio. Se propone una opción de lectura, que pone en valor nuevas formas estéticas, para presentar el nexo entre el sujeto y la naturaleza, en tanto formuladas desde argumentos críticos que desafían formas convencionales de representar esta relación y que tienden a agotar "lo natural" en discursos sostenidos en paradigmas binarios que lo identifican a un territorio concreto, exterior al sujeto y sometido a la idealización. Desde la perspectiva de los sujetos, se constata una herencia truncada del territorio, asumiendo por ello, la compleja tarea de replantear la memoria desde la corporalidad, entendiendo el cuerpo como territorio compartido, poblado de imágenes, discursos y representaciones no siempre congruentes, sino más bien, contradictorias. En Viento sur, la poesía surge como un intento de recomponer este nexo desde nuevas formas de vitalidad que inauguran trayectos territoriales que hacen partícipes a los otros, configurando en la poesía territorios compartidos, que apuesta por una enunciación colectiva.

Una segunda motivación, que fundamenta la realización de esta nota, consiste en relevar esta producción de poesía local como un asunto que merece ser reconocido y difundido en su originalidad; pues, lo "local" es un territorio que se reconfigura en la singularidad de la poesía, desde palabras
\end{abstract}


que reinauguran nuevos sentidos para "el sur", como es, entre otros, el gesto de compartir un espacio.

Atendiendo a las motivaciones precedentes, se considera en lo que sigue algunos elementos centrales del formato del libro para posteriormente ensayar una aproximación interpretativa a la poesía.

Un primer acercamiento a Viento sur, poesía en territorios compartidos, permite destacar los siguientes aspectos; se trata de un poemario de 192 páginas, publicado recién en la primavera del año 2016 por editorial Amukan. Es un libro "colectivo", pues tiene por autoras a siete poetas vinculadas a la Región del Biobío, a saber: Noelia Figueroa, Alejandra Ziebrecht, Damsi Figueroa, Camila Varas, Nelly González, María Teresa Torres y Cecilia Rubio. La contratapa revela algunos datos de sus identidades y por cierto anticipa sus "capitales culturales": todas mujeres jóvenes, con formación literaria, docentes de institutos, universidades o colegios, reconocidas por sus aportes a la literatura mediante premios, antologías y publicaciones, y que, por sobre todo, comparten territorios, a saber, las proximidades a la ciudad de Concepción.

Los poemas son precedidos por una macro-sección denominada "Presentación" (páginas 9 a 31), que en realidad corresponde a tres presentaciones del texto. La primera (páginas 9 a 16), a cargo de "las autoras" situadas "en Concepción", corresponde a breves textos escritos en forma individual por cada una de las poetas. Estos son, en su mayoría, poemas en prosa de cada una de las autoras y establece, desde ya, algunas claves significantes que facilitan la lectura, tales como, la memoria, los cuerpos, los cuatro elementos de la naturaleza, el territorio, lo femenino, entre otros. Se destaca de esta sección el siguiente texto escrito por Alejandra Ziebrecht: "El libro es así, un continuo, con interrogaciones y respuestas venidas de distintos territorios, desde diversos escenarios, donde siempre se constata la preocupación existencial de quién es y por qué está la escritura y la vida sonando a un ritmo" (10). Esta afirmación, insinúa ya desde el inicio del texto, la noción de pulsión de vida, propuesta por Sigmund Freud, entendida como Eros, que coincide con el "de los poetas y filósofos, el Eros que cohesiona todo lo viviente" ([1920]1992: 49). Es decir, Eros como aquel empuje o fuerza que promueve la cohesión y por lo tanto, el movimiento como característico de todo lo animado.

La segunda presentación es un análisis crítico del texto, titulado "Rutas 
y encuentros en Territorios del Viento Sur" (páginas 17 a 27), cuya autoría corresponde a María Teresa Aedo, académica de la Universidad de Concepción. La crítico destaca la doble codificación entre grafía y fotografía como "primera señal" del libro, que desde su interpretación, apela a sensaciones, percepciones y experiencias producidas por la dinámica propia de los elementos de la naturaleza que, a su vez, potencian el movimiento de los cuerpos y los signos desarticulando las nociones de tiempo, espacio y territorios, entre otros. De esta manera, se configuran otras lógicas de conocer, relacionarse, recordar y otras genealogías de las voces poéticas. Este dinamismo también promueve la pluralidad de las subjetividades, la ausencia de recursos como el retorno al origen y la tradición, la falta de límites. Todo se vuelve explorable, como nuevas rutas que anticipan otras travesías por los territorios compartidos.

Finalmente, la tercera "Presentación" (páginas 28 a 31) realizada por el poeta penquista Alexis Figueroa, apuesta a la inscripción del texto en la "tradición" de las voces poéticas femeninas nacionales y locales. Para Figueroa, la apuesta original de Viento sur radica en el subtítulo poesía en territorios compartidos, que alude a "la posibilidad de un territorio habitado y constituido por diferentes realidades, la presencia de una voz poética múltiple, constituida en un lugar dinámico, cuya característica esencial es diversidad y participación" (31). Además, el poeta también considera a la naturaleza como un eje con el que dialoga la escritura, en el entendido que ésta concierne a "aquello que se revela en su voluntad primigenia" (31).

El libro, de una cuidada y prolija edición, reúne alrededor de 80 poemas, escritos en verso libre, algunos dispuestos en estrofas, otros en caligramas y en su mayoría, en prosa poética. El texto presenta algunas recurrencias como la presencia de fotografías o imágenes alusivas a la naturaleza, algunos retratos de las autoras y otras que refieren a lo femenino, como muñecas o cuerpos pintados de mujer. Otra reiteración son la presentación de los textos, distribuidos por autora y cuya primera página es de diversos colores en asociación con el nombre que se le entrega a cada una de las compilaciones ${ }^{1}$.

${ }^{1}$ Las secciones de las autoras se corresponden en orden de presentación a: "La costumbre» de Noelia Figueroa que se presenta en color naranja, "El lenguaje de las olas" de Alejandra Ziebrecht en color amarillo, "Tierras raras" de Damsi Figueroa en color azul, 
No obstante, que es posible decodificar la semiosis de cada uno de los lenguajes del texto e incluso de las secciones de poemas de cada una de las autoras, es de interés en esta nota destacar algunos elementos del libro que a su vez permiten introducir un plano interpretativo para el texto, que considera como principal supuesto que los sujetos del texto al asumir la figura del nomadismo se configuran desde lo vital. Esta dimensión de lo vivo es también una forma de reestablecer el nexo entre territorio y memoria.

El primer elemento, ligado al asunto del poemario, es el título Viento Sur. Como sabemos, el viento fue un elemento muy relevante para las culturas ancestrales, pues representaba las intenciones malignas o benignas de los dioses, y en los Huilliches hay relatos que afirman que daban origen a algunos elementos ${ }^{2}$ (Montecino, 2015). También el viento sur, desde el saber popular, anticipa un estado del ambiente. Así por ejemplo se dice: "norte claro sur oscuro aguacero seguro" o "está corriendo viento norte", para anticipar el mal tiempo. El viento sur es, entonces, una clara señal de prosperidad o cuando menos, de estabilidad. Por otra parte, el subtítulo del libro poesía en territorios compartidos, inmediatamente nos remite al espacio, a la tierra, pero sin los límites impuestos por la propiedad privada. Es decir, al tratarse de aquel territorio que se comparte, el subtítulo se puede interpretar como el territorio que es de todos, a saber, la poesía que surge formando comunidad. La poesía opera, entonces, como una forma de instaurar el lazo social entre voces que circulan por espacios comunitarios.

$\mathrm{Al}$ respecto, se puede señalar que el sujeto del texto se presenta como sujeto nómade (Braidotti, 2000) ${ }^{3}$. Con ello, no se alude necesariamente a las propuestas discursivas de sujetos centrados en el desplazamiento físico o en el viaje. Se trata más bien, de la configuración de una multiplicidad de sujetos que asumen una propuesta crítica y transgresora, especialmente desde las representaciones identitarias. Así, en los textos, se presenta una

\footnotetext{
"De este cuerpo y de otros" de Camila Varas en color negro, "Terrores nocturnos" de Nelly González en color café, "Animal” de María Teresa Torres en color rojo y finalmente, "La hija menor" de Cecilia Rubio en color celeste.

${ }^{2}$ Otras culturas también han configurado relatos mitológicos en torno al viento. Por ejemplo, los selk'nam afirman la supremacía del viento oeste para soplar en todo territorio, el que resultó vencedor tras librar una batalla con los vientos de los otros puntos cardinales.

${ }^{3}$ El nomadismo según Rossi Braidotti, alude a una figura que representa "una interpretación situada, posmoderna, culturalmente diferenciada del sujeto" (2000: 30) ya sea este sujeto colonizado, feminista, etc.
} 
polifonía de voces que retratan diversas identidades en la relación consigo mismo y a su vez, en la diferencia con el otro, en distintas dimensiones temporo-espaciales y culturales; tal como se registra en la primera estrofa del poema "Náhualt" de Damsi Figueroa:

"Cierro los ojos y veo dentro de mí los ojos del animal

Soy un poeta nocturno

En mis ojos fosforece una visión" (93)

Así mismo, en los siguientes versos del poema "Reencarnaciones" de la poeta Nelly González:

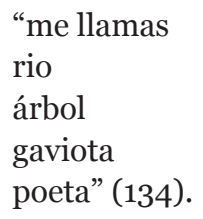

En el caso del poema de Figueroa, titulado "Náhualt", se observa una relación intercultural con la lengua y cultura del mismo nombre y con otras dimensiones temporo-espaciales; pues la visión de los ojos del animal acontece desde la imposibilidad de ver, en "cierro los ojos", durante la oscuridad de la noche. Por otra parte, la identificación con lo masculino, en "el poeta", añade también otra identidad, a saber, a la presencia del animal. Lo mismo acontece en los versos de Nelly González, donde el sujeto es nombrado al mismo tiempo, como un ser no vivo, en "rio", vivo en "árbol" y "gaviota", y humano, en "poeta".

La nomadía se presenta en todas las autoras en la enunciación de sujetos cuyos discursos adoptan diferentes formas: exilio, migración, vagancia, destierro, errancia, etc., como imaginarios de transgresión ante las políticas universalizantes, esencialistas y dualistas. A modo de ejemplo se encuentran estos versos de Camila Varas, donde la identidad rupturista del sujeto se metaforiza en la figura de la luz:

"Finalmente me canso de la imagen

Y abandonaría cualquier estructura

Que pretendiera contener mi conciencia

Lo abandonaría todo a cambio de la luz" (105) 
La configuración de estos discursos se logra además de la representación de sujetos, mediante procedimientos como la intertextualidad, la codificación en variados lenguajes, tanto oral como escrito, y la iconografía visual. En la amplia diversidad de discursos se presenta como metatexto el discurso crítico respecto al proyecto escritural, tal como en el poema "Carta a Pedro Lastra" de Cecilia Rubio, donde los primeros versos de la última estrofa son los siguientes:
"Porque escribo hoy
yo que igualmente no tengo
casi palabra
ni reino del sueño
busco acaso un poema lejano
o busco una cara
no la que hoy tendría
la que tuvimos ayer pero menos cansada
y encontré estas palabras
no para mañana sino para ayer" (173)

Viento sur, poesía en territorios compartidos es un texto que remarca otras figuras que también aluden al nomadismo, tales como, el desplazamiento, el movimiento, la oscilación, etc., que representan metáforas en clave poética de la pulsión de vida. Es decir, los sujetos del texto al asumir la figura del nomadismo se configuran desde lo vital. Los ejemplos más evidentes son: la alusión a dos formas de materia, el aire representado como viento y la tierra en la imagen de territorio.

Tal como lo entiende Benjamín Subercaseaux (1964), el movimiento es una propiedad de la materia que es condición de lo que anima y propulsa la existencia. No se trata que la materia genere movimiento, ni al revés, sino que están en estrecha relación, tan estrecha incluso, que uno es condición del otro formando un quiasmo ${ }^{4}$ que los vincula. El viento circula como lo vivo, produce el movimiento, somete e impulsa los cuerpos, los golpea y

${ }^{4}$ Noción que utiliza Ponty-Merleau (2008) y que como señala Mario Teodoro Ramírez (2013) designa: "una dualidad reversible, de entrecruzamiento y encabalgamiento recíproco: una unidad dual, diferencial, o, de otra manera, una dualidad unitaria: la composición única que producen dos sentidos inversos (una mismidad en la diferencia y una diferencia en la mismidad)". (43). 
desordena con la mayor de las versatilidades. El viento que no se ve, se experimenta mediante las sensaciones, pero también en el texto poético, como una figura que representa las subjetividades "enredadas" o confusas respecto a transmisión de la memoria de los orígenes. Así lo muestra la poeta Noelia Figueroa en su texto "Meulen"5, donde el sujeto se nombra como "arremolinada” y afirma:
"meulen enredas
los hilos de la memoria
invitas
al nido de culebras
original" (36)

El vuelo, el deseo de "tocar el cielo" y la vida como el "aleteo de un colibrí" que recobra el aliento, son también una constante en los poemas de María Teresa Torres, donde el sujeto afirma: "Busco el deseo/ El milagro que eche a volar mi inercia" (152).

Además del viento se presenta otro elemento fundamental, la tierra, que promueve lo viviente, el goce y la sensualidad de aquello que se gesta. La tierra también relata la historia enmudecida de los antepasados, se constituye en testigo de lo que fue y entrega señales de aquello que permanece aun cuando solo pueda ser percibido a través de los sentidos. De esta forma contacta con la vida que perdura incluso más allá del tiempo. Así se puede interpretar la compilación de Nelly González titulada “Terrores Nocturnos", donde la tierra muestra el rastro de quienes no están, pero que a su vez, es un indicio de su eternidad:

"No permito que me llamen por genealogías inventadas

Mis ancestras me cantan desde la tierra

Y sus voces me dictan las ausencias y dolores primitivos" (137)

Tal como se señala al inicio de esta nota, en Viento sur los sujetos asumen la misión de resignificar los orígenes y las maneras de transmitir la memoria desde la corporalidad, que a su vez representa el territorio com-

\footnotetext{
${ }^{5}$ Como afirma Montecino (2015) "el meulén o remolino de viento está asociado al Huecuve (fuerza del mal) y se piensa que trae desgracias y enfermedades” (621).
} 
partido. En éste coexiste la materia como una figura que reúne las diversas voces de los ancestros desconocidos, cuyo dolor aún está presente en los discursos de los sujetos. De esta forma, los territorios compartidos comprenden también los silencios y ausencias que han sido desplazadas por las "genealogías inventadas".

Finalmente, no se puede desconocer que el deseo de que sople Viento sur también se liga a los elementos del agua y del fuego, mediante imágenes presentes en diversos textos de las autoras, como en estos versos donde se convocan los elementos, cuya autoría pertenece a Alejandra Ziebrecht y que no obstante estar dedicados a Virginia Woolf, se pueden interpretar como señales del porvenir:

"Tus huellas retornarán al agua y al arcilla síntesis del naufragio bajo el cielo y su neblina Inflámate fémina sobre el áspero sosiego Solo tuyas son las voces” $(58)$.

\section{Referencias}

Braidotti, Rossi. (2000). Sujetos nómades. Buenos Aires: Paidós.

Freud, Sigmund. [1920] (1992). "Más allá del principio del placer", en Obras Completas, tomo XVIII. Buenos Aires: Amorrortu, 7-62.

Montecino, Sonia. (2015). Mitos de Chile. Enciclopedia de seres, apariciones $y$ encantos. Santiago: Catalonia.

Ponty-Merleau, Maurice. (2008). El mundo de la percepción. Buenos Aires: Fondo de Cultura Económica.

Subercaseaux, Benjamín. (1964). Santa Materia. Santiago: Ercilla.

Teodoro, Mario. (2013). La filosofía del quiasmo. Ciudad de México: Fondo de cultura económica.

Ziebrecht, Alejandra; Varas, Camila; Rubio, Cecilia; Figueroa, Damsi; Torres, María Teresa; González, Nelly; Figueroa, Noelia. (2016). Viento sur, poesía en territorios compartidos. Concepción: Amukan. 